\title{
RESTAURANTES ORIENTAIS E SUAS ESTRATÉGIAS SOBRE SEUS CANAIS DE MARKETING
}

\section{ORIENTAL RESTAURANTS AND THEIR STRATEGIES ON THEIR MARKETING CHANNELS}

\author{
AMANDA DOS SANTOS NEGRETI \\ Professora na União Cultural do Estado de São Paulo (UCESP) \\ Mestre e doutoranda em Agronegócio e Desenvolvimento (UNESP) \\ Orcid: http://orcid.org/0000-0001-7371-159X \\ E-mail: amanda.negreti@unesp.br
}

Rua Domingos da Costa Lopes, 780 - Jd. Itaipu - Tupã/SP CEP: 17602-496

GESSUIR PIGATTO

Professor Associado da Universidade Estadual Paulista (UNESP)

Doutor em Engenharia de Produção (UFSCar)

Professor no PPG em Agronegócio e Desenvolvimento (UNESP)

Orcid: https://orcid.org/0000-0002-5240-2381

E-mail: gessuir.pigatto@unesp.br

\author{
JOÃO GUILHERME DE CAMARGO FERRAZ MACHADO \\ Professor Associado da Universidade Estadual Paulista (UNESP) \\ Doutor em Engenharia de Produção (UFSCar) \\ Professor no PPG em Agronegócio e Desenvolvimento (UNESP) \\ Orcid: https://orcid.org/0000-0002-4084-945 \\ E-mail: jg.machado@unesp.br
}

Submissão: 13/03/2019. Revisão: 07/06/2020. Aceite: 22/07/2020. Publicação: 03/08/2020. DOI: http://dx.doi.org/10.22277/rgo.v13i3.4793

\section{RESUMO}

Diante do crescimento da preferência do consumidor por comida oriental e do aumento de restaurantes que oferecem essa culinária, o objetivo deste artigo foi caracterizar e analisar a forma de seleção de canais de distribuição e comunicação, verificando se são utilizados de maneira estratégica pelas empresas que oferecem comida oriental. Como método, utilizou-se da pesquisa exploratória e estudo de multicasos, sendo a coleta de dados realizada por meio de observação direta, análise documental e entrevista focada, com o uso de formulário aplicado junto aos gestores de seis estabelecimentos localizados no Noroeste paulista. Os resultados mostraram que os canais de distribuição utilizados por esses estabelecimentos variam entre tradicional e alternativo (delivery e food truck). Os gestores utilizam estratégias competitivas na gestão dos canais de distribuição e comunicação de seus estabelecimentos, com ênfase para a localização, o uso do ambiente e ferramentas de comunicação, conforme o canal utilizado, com destaque para o uso de redes sociais e aplicativos móveis (APP), ao oferecerem serviços de acordo com as mudanças do comportamento do consumidor. Ainda, foi possível verificar que as decisões e desdobramentos estratégicos dos gestores dos respectivos estabelecimentos são condizentes com os canais de distribuição utilizados.

Palavras-chave: Canais de distribuição. Serviço de alimentação. Estratégia. 


\begin{abstract}
Given the growing consumer preference for eastern food and the increase in restaurants offering this cuisine, the aim of this article was to characterize and analyze the form of selection of distribution and communication channels used by restaurants offering oriental food. As a method, we used the exploratory research and multisite studies, the data collection was done through direct observation, documentary analysis and focused interview, with the use of a form applied to the managers of six establishments located in the Northwest of São Paul. The results showed that the distribution channels used by these establishments vary between traditional and alternative (delivery and food trucks). It is concluded that managers use competitive strategies in the management of the distribution channels and communication of their establishments, with emphasis on the location, use of the environment and communication tools, according to the channel used, especially the use of social networks and mobile applications (APP) across all companies by offering services according to changes in consumer behavior. Also, it was possible to verify that the strategic decisions of the managers of the respective establishments are consistent with the distribution channels used.
\end{abstract}

Keywords: Distribution channels. Food services. Strategy.

\title{
1 INTRODUÇÃO
}

Um produto somente será disponibilizado ao cliente após a seleção de um canal de distribuição que facilite a busca por parte da demanda e a disponibilidade da oferta, servindo como um ponto de encontro dos usuários finais com os vendedores do produto/serviço (COUGHLAN et al., 2012).

A estratégia de um canal de distribuição depende de ações consistentes de pessoas e gestores desse canal para implementá-la, pois são nesses canais que os processos de criação de valor para o cliente são mais evidenciados dentro de uma cadeia de suprimentos, onde ocorre a conexão com clientes finais, em que o foco é a satisfação das necessidades e desejos (KOZLENKOVA et al. 2015).

Nesse sentido, a profunda transformação que a contínua digitalização da economia e os canais online estão promovendo, somado às mudanças no comportamento do consumidor, à escassez de tempo e o cotidiano atarefado dos clientes fizeram com que as decisões dos gestores do canal de distribuição passassem a ser estratégicas (VERHOEF; KANNAN; INMAN, 2015). Assim, os canais distributivos dos estabelecimentos são redesenhados para atenderem as alterações da demanda e a permanência do estabelecimento no mercado (PIGATTO; ALCÂNTARA, 2007).

Dentre os estabelecimentos que vêm alterando seus canais distributivos estão as empresas do setor alimentício que oferecem alimentação fora do lar, o chamado food service (MACHADO; PIGATTO, 2015). Até porque, ao longo da última década, o setor de alimentos observou um aumento constante da competição em um contexto de mudanças contínuas e rápidas envolvendo estilos de vida e hábitos alimentares das pessoas (ALFIERO; GIUDICE; BONADONNA, 2017). Visando melhor atender ao cliente e/ou utilizar estrategicamente suas vantagens competitivas perante seus concorrentes, surgem como formatos de canais alternativos o delivery e o food truck. 
Esses canais alternativos têm sido utilizados por diversas empresas de alimentos, nos mais diversos segmentos da culinária, entre elas os restaurantes de culinária oriental. Enquanto o food truck procura atender aos anseios de consumidores mais contemporâneos, que passaram a valorizar e priorizar novas formas de interação com as cidades, o delivery online prioriza a busca pela conveniência que, ao mesmo tempo, leva a um melhor aproveitamento do tempo do consumidor, que pode se dedicar a outras atividades, ao invés de gastar seu tempo no deslocamento trabalho-restaurante-trabalho ou casa-restaurantecasa, e até mesmo o tempo de espera para conseguir uma mesa para fazer seu pedido.

Além disso, os formatos tradicionais de restaurante possuem custos elevados para manutenção de toda a estrutura física disponibilizada e são, em alguns casos, mais formais, afastando potenciais consumidores de baixa renda e mais jovens, em busca de boa alimentação a preços justos, situações informais e que falem a sua língua. De acordo com Kotler, Kartajaya e Setiawan (2012, p. 107), frequentemente o maior problema de vender para populações com renda mais baixa é o acesso, ou seja, muitos produtos, serviços e informações não estão prontamente acessíveis. Neste caso, "os dois elementos do mix de marketing mais afetados pela falta de acesso são ponto (distribuição) e promoção (comunicação)".

Diversos estudos abordam o tema restaurante e suas estratégias, focando em maneiras de atração e permanência do consumo, buscando a compreensão do papel da comunicação (KIM; KIM, 2019), o uso de mídias sociais (OJI; IWU; HAYDAM, 2017), as experiências (LIU; WU; WANG, 2020) e o posicionamento da marca (CASTILLO-VILLAR; VILLASANTE-ARELLANO, 2020). Entretanto, poucos trabalhos abordam o setor de restaurantes e o uso estratégico dos canais de distribuição e comunicação de forma conjunta (BERSELLI et al., 2018) e menos ainda sugerindo melhorias do negócio para os restaurantes orientais (LIANG; CHEN, 2020).

De acordo com os dados apresentados pela Abresi (2016) e ABF (2018), houve uma expansão considerável de restaurantes orientais instalados no Brasil, devido à alta demanda por alimentos benéficos para a saúde. De acordo com Barbosa et al. (2010), com base em fatores de demanda da população brasileira, há alta tendência pelo consumo de alimentos que apresentam a sensorialidade, prazer, saudabilidade e bem-estar, sendo características apresentadas pelos alimentos servidos em restaurantes orientais. Somente na cidade de São Paulo há cerca de três mil restaurantes orientais (como cardápio exclusivo e/ou que incluem a culinária oriental em seus menus), enquanto no país todo, são mais de 11.500 estabelecimentos do tipo (ABF, 2018). O aumento da demanda e o crescimento do número de restaurantes instalados pelo país geraram novas necessidades, como manutenção dos requeridos padrões de atendimento, que envolve utilizar diferentes tipos de canais de distribuição e, consequentemente, estratégias de comunicação como forma desses estabelecimentos se manterem competitivos (FORMIGONI, 2017).

Diante do exposto, e considerando o aumento de restaurantes orientais, a tendência por alimentação mais saudável e sensorial, a variedade do formato de canais de distribuição e a busca por uma melhor experiência de consumo, decorrentes do uso estratégico dos canais de marketing, o problema de pesquisa deste estudo foi "como os restaurantes orientais utilizam os seus respectivos canais de distribuição e comunicação de forma estratégica?"

Assim, o presente artigo teve por objetivo, caracterizar e analisar a forma de seleção de canais de distribuição e comunicação, verificando se os mesmos são utilizados de maneira estratégica pelas empresas que oferecem comida oriental.

$O$ artigo foi estruturado em cinco seções, além desta introdução. A segunda seção apresenta o referencial teórico, que aborda e discute os conceitos de canais de distribuição, 
comunicação e os restaurantes, como agregação de valor do produto/serviço oferecido. Em seguida, é apresentado o método utilizado na pesquisa. A seção seguinte apresenta os principais resultados obtidos, posteriormente, esses resultados são discutidos e, por fim, são apresentadas as conclusões da pesquisa.

\section{REFERENCIAL TEÓRICO}

Os canais de marketing estão por trás de todo e qualquer produto/serviço que os consumidores finais ou compradores de corporações adquirem em qualquer lugar e momento, facilitando a busca por parte de demandantes e ofertantes, uma vez que os usuários finais não sabem ao certo onde encontrar produtos ou serviços que procuram, assim como muitos vendedores não sabem como alcançar os usuários finais (COUGHLAN et al., 2012; TELLES; STREHLAU, 2017).

Os profissionais utilizam três tipos de canais de marketing a fim de atingir um mercadoalvo os canais de distribuição, de comunicação e de serviços (KOTLER; KELLER, 2012). A escolha de cada um deles afeta as decisões referentes à comercialização do produto.

\subsection{CANAIS DE DISTRIBUIÇÃO}

De acordo com Rosenbloom (2014) e Silva et al. (2016), os canais de distribuição são considerados como todas as movimentações de um produto, desde sua concepção, incluindo a transferência de posse entre os vários níveis, passando pela transformação e distribuição. Sob essa perspectiva, os agentes integrantes dos canais de distribuição procuram entregar o produto da melhor maneira possível ao usuário final. O restaurante, como um membro do canal de distribuição, contribui na geração de valor do produto oferecido ao cliente, devido à interação e ao relacionamento que ocorre durante seus atendimentos (KOUFIE; KESA, 2020).

Nesse sentido, há diversos canais de distribuição, em que os gestores buscam manterse no mercado e atender às novas exigências do consumidor. Existem os canais tradicionais, estabelecimentos físicos que recebem os clientes para alimentação, como restaurantes, padarias, lanchonetes, pizzarias e os formatos de canais alternativos, como delivery, containers, food trucks e APPs, que vem ganhando relevância no mercado de alimentação.

Entre os formatos de canal alternativo estão aqueles que, com o auxílio de catálogos e/ou tecnologia, favorecem o processo do cliente efetuar a compra sem a necessidade de sair de casa, realizando pedidos por meio de telefone, aplicativos ou redes sociais e o fornecedor entrega o produto solicitado em seu domicílio (COUGHLAN et al., 2012). Esse formato de canal, o delivery, está tradicionalmente associado às pizzarias e lanchonetes que, a partir do pedido do cliente, entregam o produto pronto para o consumo.

Outro formato de canal de distribuição alternativo é o food truck, onde os produtos são armazenados em um veículo (carro/caminhão/trailer) e vendidos ao longo do percurso do veículo, ou em local previamente selecionado, com o auxílio da tecnologia, com a qual o fornecedor comunica aos seus clientes o local em que seu negócio se encontra naquele dia ou horário (COUGHLAN, 2012). Para McLaughlin (2009), o food truck já representou o ponto mais baixo da realização culinária, relacionando-se à imagem de cachorros-quentes fornecidos sem higienização. Com o decorrer do tempo, essa imagem deixou de existir, atualmente até mesmo alguns chefs renomados têm migrado para esse segmento, o qual é adequado para uma situação de crise financeira, por requerer um menor aporte inicial de capital em relação a um restaurante fixo (ALFIERO; GIUDICE; BONADONNA, 2017; DE SOUZA BISPO; ALMEIDA, 2020). 
Esses formatos alternativos são escolhidos pelas empresas a fim de criar vantagem estratégica, uma vez que um sistema de canal forte é um ativo competitivo, que conforme Palmatier et al. (2016), quando não replicado por outras empresas o torna fonte de uma vantagem competitiva sustentável. De acordo com Porter e Miller (1985), para a empresa possuir uma vantagem estratégica é preciso ter claramente os seus objetivos para a condução de uma posição competitiva favorável, sustentável e lucrativa perante os concorrentes. Para os autores, na estratégia competitiva, parte-se do princípio da relação entre a empresa e o ambiente externo, onde é possível haver limitações de atividades inerentes à empresa e novas oportunidades a serem exploradas.

\subsection{CANAIS DE COMUNICAÇÃO}

Entre os canais de comunicação, Kotler e Keller (2012) apontam uma diversidade de meios pelos quais as organizações enviam e recebem mensagens dos consumidores-alvo, como revistas, jornais, rádio, televisão, telefone, outdoors, cartazes e internet, entre outros.

Entretanto, uma comunicação eficaz necessita de uma estratégia de comunicação, que precisa ser planejada considerando os objetivos estratégicos da organização. Nesse sentido, Pratamawaty, Cahyadini e Veronica (2018) destacam alguns elementos-chave para uma estratégia de comunicação eficaz: (i) a escolha do meio, como forma de alcance do consumidor; (ii) a estrutura da mensagem, determinando o apelo e considerando o tipo de linguagem (verbal e/ou não verbal); e (iii) o público selecionado, compreendendo suas condições sociais e econômicas.

No âmbito dos restaurantes orientais, a escolha estratégica do canal de comunicação varia desde o tradicional, como os anúncios por meio de outdoors, jornais, rádios ou TV, até os meios digitais, que vem tendo seu uso ampliado com a popularização de diferentes tecnologias de informação e comunicação (TIC) (LIANG; CHEN, 2020).

O uso da estratégia de comunicação por meio das TIC acelera o fluxo de capital, serviços, produtos, tecnologias e conhecimento da organização, neutralizando as restrições impostas pelas distâncias geográficas e facilitando a integração comercial entre os espaços produtivos (SALAZAR-SOLANO et al., 2018).

Além desses benefícios, as organizações se aproximam dos consumidores, desencadeando uma integração comercial a partir da interação social. Santos, Alves e Brambilla (2016), por exemplo, explicam que as ferramentas de comunicação online, como as redes sociais, possibilitam a cocriação de valor, isto é, a transferência de diálogo e a troca de informação mútua, entre os comerciantes e clientes. É por meio de redes sociais, como o Instagram, Facebook e WhatsApp que as empresas visualizam a oportunidade de aproximação com os consumidores, iniciando e desenvolvendo a interação entre ambos conforme as respostas aos comentários realizados nestas mídias.

As mídias sociais permitem aos gestores dos restaurantes o acesso de informações dos consumidores, como os dados pessoais, perfil, preferências e uma melhor compreensão sobre o que as pessoas comentam acerca dos seus empreendimentos, pratos e serviços oferecidos, como uma das vantagens que auxiliam na melhoria de desempenho (NEEDLES; THOMPSON, 2013). Sung, Tao, Slevitch (2020) também relatam o uso das mídias sociais por restaurantes auxiliando no fortalecimento da intenção de compra e na criação de um sentimento positivo para o consumo auxiliando, ainda, na atração de novos consumidores, na ampliação do alcance de pessoas, e na rápida disseminação de conteúdo em um curto período de tempo.

Entretanto, essas ferramentas online apresentam dificuldades para sua gestão de forma estratégica, requerendo uma melhor administração das informações de consumo, o 
que inclui conhecer o perfil dos consumidores, suas preferências e exigências, podendo ocasionar, muitas vezes, custos adicionais na contratação de um profissional para esse fim (BERSELLl et al., 2018).

\subsection{SERVIÇOS APLICADOS AO SETOR DE ALIMENTAÇÃO}

A fim de realizar transações com compradores potenciais, as empresas também utilizam os canais de serviços, incluindo hotelaria, lavanderia, hospitais, adegas e restaurantes, sendo classificados como intermediários na escala de identificação dos setores econômicos vinculados a produtos ou serviços, onde se encontram no ponto intermediário entre o setor de bens e o de serviços (LOVELOCK; WIRTZ; HEMZO, 2011; MACHADO; PIGATTO, 2015).

Para Lovelock, Wirtz, Hemzo (2011), a classificação intermediária, entre o setor de bens e serviços, coloca os produtos oferecidos em uma escala de dominação entre a tangibilidade e a intangibilidade.

Nesse sentido, os produtos oferecidos em restaurantes encontram-se próximos ao centro da escala dessa denominação por incluir um serviço intangível, devido à confecção/preparação do prato, ao atendimento ao cliente, assim como à presença do consumidor em determinadas ocasiões para que esse serviço ocorra, e por incluir um bem tangível, representado pelo prato (alimento). Conforme apontam Ramanathan, Di e Ramanathan (2016), em um restaurante os clientes não experimentam apenas a comida, mas também os serviços oferecidos durante a refeição. Por essas razões, são considerados ambíguos, isto é, são classificados tanto como tangíveis quanto intangíveis (LOVELOCK; WIRTZ; HEMZO, 2011).

Além dos atributos de tangibilidade e intangibilidade dos produtos oferecidos pelo setor de alimentação, há outras características que favorecem a sua classificação entre bens e serviços, conforme o Quadro 1.

Os restaurantes, por meio da prestação de serviços no setor alimentício, possuem papel importante na integração do canal distributivo: a aproximação aos clientes finais; a agregação de valor aos produtos oferecidos, informando a qualidade/atributos do mesmo, não se restringindo em oferecer somente alimentos prontos (CARMO, 2012). Liang e Chen (2020) acrescentam ainda, a capacidade de oferecer aos clientes uma atmosfera exótica nos restaurantes orientais, como uma oportunidade para que eles possam conhecer e apreciar outra cultura, provando o alimento criado à base de tradições locais e culturais.

Carmo (2012) aponta outra experiência proporcionada aos consumidores, relacionada à maneira pelo qual o produto e o serviço são oferecidos, visando responder de maneira satisfatória às suas exigências contemporâneas decorrente das mudanças no comportamento do consumidor. Neste sentido, Machado e Pigatto (2015) e Xue et al. (2020) relacionam as opções de vendas por meio de catálogos, aplicativos e as compras online, que expandem os benefícios ao cliente, reduzindo o esforço de compra, o tempo de deslocamento até o estabelecimento e a espera, quando é preciso aguardar por uma mesa e o preparo da refeição. 
Restaurantes orientais e suas estratégias sobre seus canais de marketing

Quadro 1- principais características de serviços no setor de alimentação

\begin{tabular}{|c|c|c|}
\hline \multirow{2}{*}{$\begin{array}{l}\text { Características do } \\
\text { Serviço }\end{array}$} & \multicolumn{2}{|c|}{$\begin{array}{l}\text { Representatividade das características do serviço em relação aos atributos do } \\
\text { setor alimentício }\end{array}$} \\
\hline & Alta representatividade & Baixa representatividade \\
\hline $\begin{array}{l}\text { Simultaneidade/ } \\
\text { Inseparabilidade }\end{array}$ & $\begin{array}{l}\text { Produção da refeição e consumo } \\
\text { imediato no local do restaurante. } \\
\text { Muitas vezes o consumidor está } \\
\text { "experimentando" o serviço dentro das } \\
\text { instalações da empresa }\end{array}$ & $\begin{array}{l}\text { Resultado do prato - os consumidores não } \\
\text { visualizam a criação do processo e os } \\
\text { alimentos são consumidos nos lares }\end{array}$ \\
\hline Heterogeneidade & $\begin{array}{l}\text { O serviço depende, muitas vezes, do } \\
\text { trabalho humano, o que dificulta a } \\
\text { homogeneidade da produção }\end{array}$ & $\begin{array}{l}\text { Exige um maior treinamento dos } \\
\text { funcionários para a padronização do } \\
\text { resultado do processo. Alimentos } \\
\text { produzidos com o auxílio de máquinas e } \\
\text { equipamentos }\end{array}$ \\
\hline Intangibilidade & $\begin{array}{l}\text { Mais da metade do valor do prato } \\
\text { solicitado vem da prestação de serviços. } \\
\text { Pagamento é referente à preparação } \\
\text { por parte do cozimento, atendimento } \\
\text { do garçom, estacionamento e ambiente }\end{array}$ & $\begin{array}{l}\text { Natureza do ato da prestação de serviços } \\
\text { do restaurante são ações tangíveis, } \\
\text { dirigidas aos clientes, o qual o cliente } \\
\text { precisa estar fisicamente presente para } \\
\text { receber a prestação desse serviço. O } \\
\text { resultado do prato representa a } \\
\text { tangibilidade }\end{array}$ \\
\hline $\begin{array}{l}\text { Perecebilidade/ } \\
\text { Inestocabilidade }\end{array}$ & $\begin{array}{l}\text { Criação dos alimentos e consumo } \\
\text { imediato no local. Espaço vazio de uma } \\
\text { mesa no restaurante não poderá ser } \\
\text { somado à capacidade total do local na } \\
\text { noite seguinte }\end{array}$ & $\begin{array}{l}\text { Os prestadores de serviços são } \\
\text { dependentes de recursos e instalações } \\
\text { para atender aos clientes. A capacidade } \\
\text { de instalações do restaurante, mesas, } \\
\text { cadeiras presentes no ambiente, possuem } \\
\text { características de fácil estocabilidade }\end{array}$ \\
\hline
\end{tabular}

Fonte: Adaptado de Fitzsimmons e Fitzsimmons (2011), Lovelock, Wirtz e Hemzo (2011) e Machado e Pigatto (2015), Ramanathan, Di e Ramanathan (2016).

\section{PROCEDIMENTOS METODOLÓGICOS}

A fim de atender ao objetivo proposto, empregou-se a pesquisa exploratória com o estudo de multicasos. Para a coleta de dados, utilizou-se da observação direta; entrevista focada, com a aplicação do formulário junto aos gestores das empresas pesquisadas e análise documental. Seguidamente, realizou-se a descrição da pesquisa a partir da triangulação dos dados coletados. Os procedimentos metodológicos encontram-se expressos resumidamente na Figura 1.

De acordo com Raupp e Beuren (2003), a pesquisa exploratória é utilizada para explorar um assunto, possibilitando ao pesquisador conhecê-lo com maior profundidade, de modo a torná-lo mais claro e contribuir com questões importantes para a condução da pesquisa. Dessa forma, buscou-se conhecer com maior profundidade as diferentes formas de seleção (estratégica) de canais de distribuição utilizados pelos gestores dos restaurantes, assim como a estratégia de comunicação utilizada, buscando entender como isso afeta a competitividade e as decisões estratégicas utilizadas pelas empresas estudadas. A base teórica sobre canais de marketing, focando na utilização dos canais de distribuição e de comunicação de forma estratégica, a fim de atingir o mercado-alvo e potencializar decisões de posicionamento da marca e diferenciação do serviço, trouxe à luz algumas questões norteadoras, construídas para a condução dessa pesquisa. São elas: "De que forma os restaurantes de comida oriental utilizam seu(s) canal(is) de distribuição buscando um posicionamento estratégico no mercado em que atuam?" e "O(s) canal(is) de comunicação 
utilizado(s) é(são) compatível(is) com o público-alvo e sustentam a escolha estratégica do canal de distribuição?".

Para respondê-las, foi utilizada a técnica do estudo de multicasos, pois de acordo com Yin (2005), sua essência é a tentativa de esclarecer uma decisão ou um conjunto de decisões, em identificar o porquê foram escolhidas e de que forma foram implementadas.

Figura 1 - procedimentos metodológicos utilizados

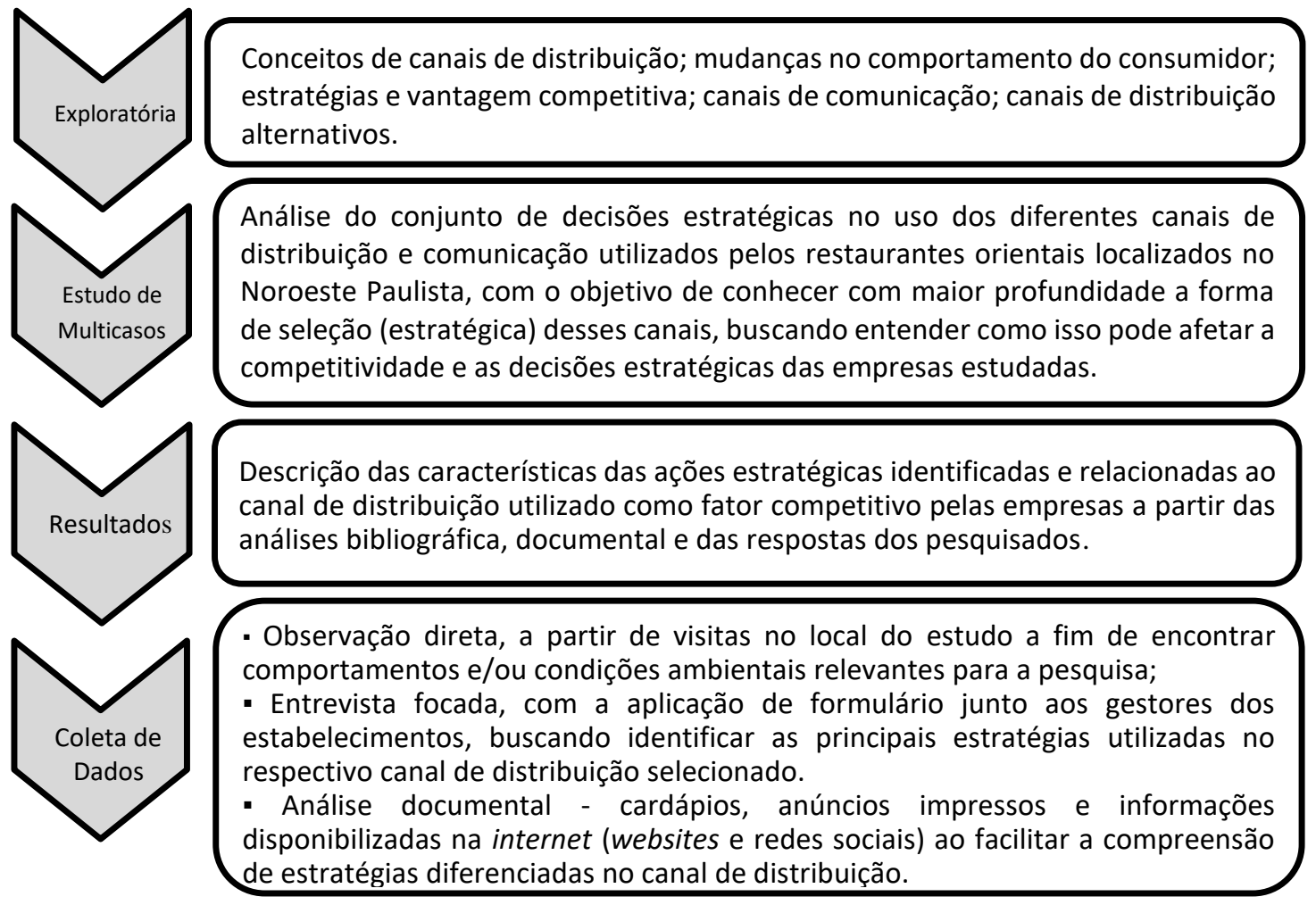

Fonte: Elaborada pelos autores

Para Yin (2005) e Creswell (2014), o estudo de multicasos pode ser utilizado por meio de uma coleta de dados profunda envolvendo múltiplas fontes de informações ricas no contexto. Por essa razão, a pesquisa utilizou-se de diferentes técnicas para a coleta de dados, buscando esclarecer como foram decididos e executados pelos gestores dos empreendimentos o conjunto de decisões e o tipo de canal, no que se refere à sua escolha estratégica. Dentre elas, destacam a observação direta, a entrevista focada, com a aplicação de entrevista junto aos gestores, guiada por questões semiestruturadas, e a análise de documentos (websites, cardápios e redes sociais), a fim de identificar informações estratégicas no contexto dos canais de distribuição escolhidos e da estratégia de comunicação utilizada.

A observação direta foi realizada nas visitas de campo aos locais de estudo, para encontrar comportamentos ou condições ambientais relevantes (YIN, 2005), a fim de identificar questões complexas acerca dos canais de distribuição, como os comportamentos dos consumidores, atendentes e garçons, e a entrega do serviço, incluindo a maneira como os alimentos são servidos. As condições ambientais de cada canal, como luz, som ambiente, organização geral, foram observadas, por serem fatores que podem afetar a competitividade e as decisões estratégicas dos restaurantes.

A entrevista com os gestores das empresas pesquisadas teve duração aproximada de uma hora cada. A condução da entrevista possibilitou a adição de outras questões além 
daquelas preestabelecidas anteriormente, buscando uma melhor compreensão das estratégias utilizadas.

As questões preestabelecidas foram padronizadas e aplicadas a todos os gestores, permitindo a comparação das respostas e a compreensão das estratégias utilizadas pelos gestores de cada formato de canal de distribuição (LAKATOS; MARCONI, 2008)

A análise documental completou a coleta de dados, com a análise de cardápios, anúncios impressos e informações disponibilizadas nos websites e nas redes sociais dos estabelecimentos, facilitando a compreensão de estratégias utilizadas. Para Yin (2005) e Gil (2008), essa técnica de coleta de dados abrange a coleta de materiais que não receberam qualquer abordagem analítica científica, constituindo uma fonte rica de dados, como por exemplo, cartas, recortes de jornais e outros artigos divulgados nas mídias.

A escolha dessas técnicas possibilitou a triangulação dos dados, que tem por objetivo a confirmação do mesmo fato por meio de diversas evidências, permitindo que o pesquisador entre em contato com uma diversidade de questões históricas, comportamentais e de atitudes, contribuindo para a elaboração de conclusões e descobertas mais consistentes (YIN, 2005).

Os seis casos selecionados para a pesquisa foram definidos por conveniência dos pesquisadores, por atender a critérios como: comercializar comida oriental no momento da pesquisa, utilizar diferentes formatos de comercialização e disponibilidade dos gestores para participação da pesquisa. Para preservar o anonimato das informações, as empresas foram nomeadas com letras: " $x$ " para as empresas que utilizam canais de distribuição tradicional, " $y$ " para as que utilizam o formato alternativo delivery e " $z$ " para os empreendimentos que utilizam o formato alternativo food truck. Os números indicam a localização: 1 para Araçatuba/Birigui e 2 para Tupã. O Quadro 2 apresenta a legenda informativa das denominações dos restaurantes com seus respectivos tipos de canais de distribuição.

Quadro 2 - Tipos de formatos (canais de distribuição) das empresas estudadas e a conceituação para o presente trabalho

\begin{tabular}{|c|c|c|c|}
\hline $\begin{array}{c}\text { Denominação do } \\
\text { restaurante }\end{array}$ & $\begin{array}{l}\text { Canais de } \\
\text { distribuição } \\
\text { utilizados }\end{array}$ & $\begin{array}{c}\text { Canal de } \\
\text { distribuição } \\
\text { principal }\end{array}$ & Conceituação \\
\hline "X" & $\begin{array}{c}\text { Tradicional e } \\
\text { Delivery }\end{array}$ & Tradicional & $\begin{array}{l}\text { Prestação de serviços alimentícios fora do lar, } \\
\text { oferecidos em estabelecimentos fixos para o cliente } \\
\text { final (MACHADO; PIGATTO, 2015). }\end{array}$ \\
\hline "Y" & Delivery e balcão & Delivery & $\begin{array}{l}\text { Canal alternativo com o auxílio de catálogos e/ou } \\
\text { tecnologia no favorecimento deste processo, onde o } \\
\text { cliente efetua a compra, sem a necessidade de sair } \\
\text { de casa, com a entrega domiciliar do produto } \\
\text { solicitado (COUGHLAN et al., 2012). }\end{array}$ \\
\hline “Z” & $\begin{array}{c}\text { Food Truck e } \\
\text { Delivery }\end{array}$ & Food Truck & $\begin{array}{l}\text { Produtos são carregados em um veículo - carro, } \\
\text { caminhão ou trailer - e são vendidos no percurso. A } \\
\text { venda pode ser auxiliada por meio da tecnologia, } \\
\text { onde o fornecedor comunica aos seus clientes o } \\
\text { local em que seu estabelecimento se encontra } \\
\text { (COUGHLAN et al., 2012). }\end{array}$ \\
\hline
\end{tabular}

Fonte: Elaborado pelos autores.

As empresas estudadas localizam-se nos municípios de Araçatuba, Birigui e Tupã, no Noroeste Paulista, que juntos somam 768 estabelecimentos (1\% do estado paulista), classificados em suas atividades econômicas como restaurantes e/ou outras unidades que oferecem serviços alimentícios e bebidas, representando diversas culinárias, dentre elas, 
árabes, brasileiras, chinesas, italianas e japonesas (IBGE, 2018). Estes municípios foram selecionados pela forte cultura oriental desde a chegada de imigrantes japoneses, mantendo a cultura e cultivando hábitos alimentares orientais desde então (MAZZINI; CHIAVENATO, 2008; TUPÃ, 2015).

\section{RESULTADOS}

As empresas que utilizam canais de distribuição tradicionais estão há mais tempo no mercado, quando comparadas às empresas de delivery e food truck, demonstrando a necessidade dos novos entrantes buscarem alternativas diferentes de atuação em relação aos estabelecimentos já existentes, como estratégia para se firmarem em um mercado bastante competitivo e com poucas barreiras à entrada, como o setor de alimentação.

A maior parte dos negócios (83\%) funciona no período noturno, abrindo apenas para o jantar. Apenas a empresa Z2 informou atender clientes em qualquer horário e local, incluindo eventos festivos durante a madrugada, diferenciando-se dos demais em relação ao horário de funcionamento, garantindo uma posição favorável e lucrativa (Quadro 3).

Quadro 3 - Caracterização das empresas

\begin{tabular}{|c|c|c|c|c|c|c|}
\hline & \multicolumn{6}{|c|}{ Empresas } \\
\hline & $\mathrm{X} 1$ & $\mathrm{X} 2$ & Y1 & Y2 & Z1 & $\mathbf{Z 2}$ \\
\hline $\begin{array}{l}\text { Tempo de } \\
\text { existência }\end{array}$ & 04 anos & 25 anos & 04 anos & 05 meses & 06 meses & 06 meses \\
\hline $\begin{array}{c}\text { Horários de } \\
\text { funcionamento }\end{array}$ & $\begin{array}{l}\text { Terça-feira } \\
\text { ao } \\
\text { Domingo, } \\
\text { das } 19 \mathrm{~h} \text { às } \\
23 \mathrm{~h} .\end{array}$ & $\begin{array}{c}\text { Terça-feira } \\
\text { ao Sábado, } \\
\text { das } 18 \mathrm{~h} . \\
\text { às } 22 \mathrm{~h} . \mathrm{e} \\
\text { Domingo, } \\
\text { das } 11 \mathrm{~h} . \text { às } \\
14 \mathrm{~h} .\end{array}$ & $\begin{array}{c}\text { Segunda- } \\
\text { feira ao } \\
\text { Sábado, } \\
\text { das } 18 \mathrm{~h} \text { às } \\
23 \mathrm{~h} .\end{array}$ & $\begin{array}{c}\text { Quinta-feira } \\
\text { ao Domingo, } \\
\text { das } 19 \mathrm{~h} \text {. às } \\
23 \mathrm{~h} .\end{array}$ & $\begin{array}{l}\text { Todos os dias da } \\
\text { semana, a partir } \\
\text { das } 18 \mathrm{~h} .\end{array}$ & $\begin{array}{l}\text { Sem dia e } \\
\text { horário fixo, } \\
\text { oferece } \\
\text { serviços em } \\
\text { eventos } \\
\text { festivos } \\
\text { durante a } \\
\text { madrugada }\end{array}$ \\
\hline $\begin{array}{l}\text { Quantidade de } \\
\text { funcionários }\end{array}$ & 25 & 10 & 05 & 08 & 04 & 01 \\
\hline Público-alvo & $\begin{array}{c}\text { Classe } \\
\text { social “A" } \\
\text { e "B+". }\end{array}$ & $\begin{array}{c}\text { Classe } \\
\text { social "A" e } \\
\text { "B+". }\end{array}$ & $\begin{array}{c}\text { Classe } \\
\text { social "B" e } \\
\text { " } C \text { ". }\end{array}$ & $\begin{array}{l}\text { Jovens e as } \\
\text { pessoas que } \\
\text { estão } \\
\text { conectadas } \\
\text { no } \\
\text { Facebook. }\end{array}$ & $\begin{array}{l}\text { Toda e qualquer } \\
\text { pessoa que } \\
\text { passar na rua de } \\
\text { um compromisso } \\
\text { para outro torna- } \\
\text { se cliente. }\end{array}$ & Jovens. \\
\hline $\begin{array}{l}\text { Quantidade de } \\
\text { clientes } \\
\text { atendidos } \\
\text { mensalmente }\end{array}$ & $\begin{array}{c}3.600 \\
\text { presencial } \\
+ \\
432 \\
\text { delivery. }\end{array}$ & $\begin{array}{c}1.400 \\
\text { presencial } \\
+ \\
400 \\
\text { delivery. }\end{array}$ & $\begin{array}{c}810 \\
\text { presencial } \\
+ \\
870 \\
\text { delivery. }\end{array}$ & $\begin{array}{c}280 \\
\text { presencial + } \\
1.120 \\
\text { delivery. }\end{array}$ & $\begin{array}{c}2.650 \text { presencial } \\
+ \\
670 \text { delivery. }\end{array}$ & $\begin{array}{c}480 \text { presencial } \\
+ \\
120 \text { delivery. }\end{array}$ \\
\hline
\end{tabular}

Fonte: Elaborado pelos autores com base na pesquisa de campo.

A pesquisa identificou que os canais alternativos delivery e food truck possuem menor quantidade de funcionários na execução dos serviços, comparado às empresas que utilizam o canal tradicional, sendo essa característica uma das principais motivações para sua escolha. Além do menor custo com contratação de funcionários, sendo desnecessário diversos garçons para servirem os clientes, os entrevistados relataram como vantagem do delivery e do food truck sobre os canais tradicionais, o menor investimento financeiro na construção e/ou locação do ambiente, por necessitarem de espaço físico reduzido para o preparo dos alimentos, dado que a maior parte dos pedidos é realizada a partir da internet e telefone, e o 
consumo do alimento ocorre no local onde o consumidor se encontra e não dentro do estabelecimento comercial.

O público-alvo de cada negócio foi apontado pelos próprios gestores a partir do entendimento que os mesmos possuem sobre seus clientes. Os gestores do canal tradicional e um dos gestores do canal alternativo descreveram seu público-alvo a partir das classes sociais, enquanto os demais os descreveram pela idade. Entretanto, os gestores não conseguiram definir qual público-alvo tem acesso aos anúncios veiculados na internet, seja por idade ou renda.

Foram identificados também os meios de divulgação, a forma como as empresas recebem os pedidos para a entrega por delivery e os meios de comunicação com os seus consumidores, conforme ilustrado no Gráfico 1.

Gráfico 1 - Meios de divulgação, recebimento de pedidos e canais de comunicação da empresa

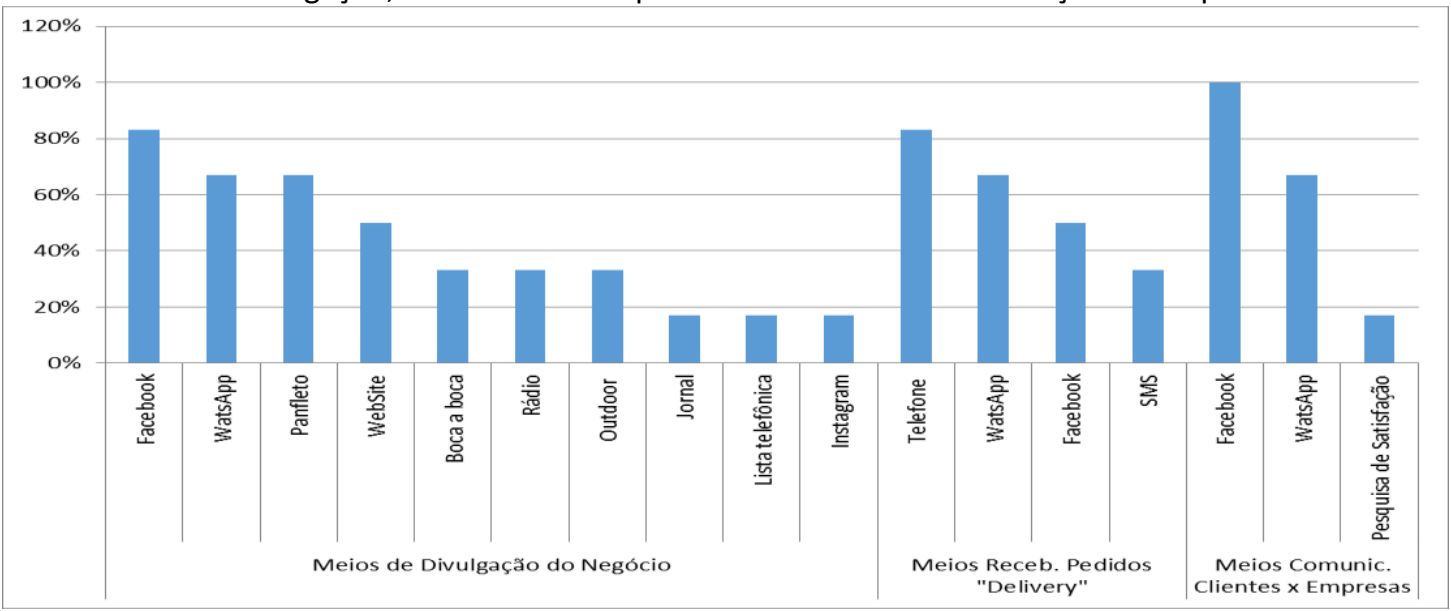

Fonte: Elaborado pelos autores com base na pesquisa de campo.

Em termos de divulgação, as principais ferramentas de comunicação escolhidas pelas empresas foram: Facebook (83\%), WhatsApp (67\%), ambos utilizados majoritariamente pelas empresas de canais alternativos, e panfletos (67\%), distribuídos tanto pelos estabelecimentos de canal alternativo como tradicional. Apesar do uso de ferramentas digitais, os canais alternativos ainda tem nos panfletos em papel, distribuídos aleatoriamente nas ruas, um instrumento de divulgação do estabelecimento.

Os panfletos continham informações do cardápio, contato telefônico, endereços dos websites, redes sociais e aplicativos, ampliando, assim, as possibilidades de realização do pedido sem a necessidade do cliente sair de casa, além de alcançar um maior número de pessoas, independentemente da idade ou renda.

O telefone e o WhatsApp representam mais de $60 \%$ dos meios utilizados para o recebimento dos pedidos, especialmente os de entrega "delivery".

Todas as empresas interagem com os clientes por meio de redes sociais, com destaque para o uso do Facebook (100\%), inclusive a empresa X1, que realiza pesquisa de satisfação no local, com questões relativas à qualidade do produto e atendimento.

O Quadro 4 apresenta as estratégias adotadas pelos gestores de acordo com o canal de distribuição e suas opiniões quanto à vantagem competitiva dos canais distributivos escolhidos. 
Quadro 4-Estratégias por meio dos canais de distribuição utilizados e percepção dos gestores

\begin{tabular}{|c|c|c|c|c|}
\hline Empresas & Localização & Ambiente & $\begin{array}{l}\text { Frases de } \\
\text { divulgação }\end{array}$ & $\begin{array}{c}\text { Motivo - } \\
\text { Canal distrib. } \\
\text { (Opinião } \\
\text { gestores) } \\
\end{array}$ \\
\hline X1 & $\begin{array}{l}\text { Próximo a outros } \\
\text { restaurantes. }\end{array}$ & $\begin{array}{l}\text { Iluminação: Baixa. Espaço: Espaçoso, } \\
\text { uma casa com ambientes separados para } \\
\text { o atendimento, espaço reservado para o } \\
\text { preparo de drinks. Decoração: Adesivos } \\
\text { de parede com desenhos orientais. } \\
\text { Climatizado: Sim. Som ambiente: Não. } \\
\text { Garçons: Vestidos com traje oriental. }\end{array}$ & $\begin{array}{c}\text { Convida o } \\
\text { cliente a } \\
\text { visitar seu } \\
\text { estabelecime } \\
\text { nto. }\end{array}$ & $\begin{array}{l}\text { Qualidade do } \\
\text { alimento e } \\
\text { atendimento. }\end{array}$ \\
\hline $\mathbf{X} 2$ & $\begin{array}{l}\text { Distante de } \\
\text { outros } \\
\text { restaurantes. } \\
\text { Facilidade para } \\
\text { vaga de } \\
\text { estacionamento. }\end{array}$ & $\begin{array}{l}\text { lluminação: Baixa. Espaço: Espaçoso, } \\
\text { bancada de alimentos no centro para os } \\
\text { clientes se servirem. Decoração: Artigos } \\
\text { decorativos pendurados no teto. } \\
\text { Climatizado: Não. Som ambiente: Sim. } \\
\text { Garçons: uniformizados normalmente. }\end{array}$ & $\begin{array}{l}\text { Enfatiza que } \\
\text { é um } \\
\text { restaurante, } \\
\text { de formato } \\
\text { tradicional. }\end{array}$ & $\begin{array}{l}\text { Qualidade do } \\
\text { alimento. }\end{array}$ \\
\hline Y1 & $\begin{array}{l}\text { Distante de } \\
\text { outros } \\
\text { restaurantes. }\end{array}$ & $\begin{array}{l}\text { lluminação: Clara. Espaço: Pequeno para } \\
\text { a realização de pedidos (balcão), } \\
\text { cadeiras para a espera do produto, com } \\
\text { um painel de senhas. Decoração: } \\
\text { Nenhuma. Climatizado: Sim. Som } \\
\text { ambiente: Não. Garçons: Inexistente. }\end{array}$ & $\begin{array}{l}\text { Transmite } \\
\text { mensagem de } \\
\text { rapidez e } \\
\text { agilidade. }\end{array}$ & Preço. \\
\hline Y2 & $\begin{array}{l}\text { Distante de } \\
\text { outros } \\
\text { restaurantes. }\end{array}$ & $\begin{array}{l}\text { Iluminação: Clara. Espaço: Pequeno, } \\
\text { com balcão, onde ficam os atendentes. } \\
\text { Na parte externa, há espaço pequeno, } \\
\text { somente três mesas, caso o cliente opte } \\
\text { se alimentar no local. Decoração: } \\
\text { Nenhuma. Climatizado: Sim (ambiente } \\
\text { da espera do produto). Não (ambiente } \\
\text { do consumo do produto). Som } \\
\text { ambiente: Não. Garçons: Inexistente. Ao } \\
\text { selecionar a opção de se alimentar no } \\
\text { local, o próprio cliente deverá se servir e } \\
\text { retirar seus pedidos no balcão. }\end{array}$ & $\begin{array}{c}\text { Insinua } \\
\text { instantaneida } \\
\text { de na } \\
\text { confecção } \\
\text { dos pratos. }\end{array}$ & $\begin{array}{c}\text { Delivery, } \\
\text { como um } \\
\text { diferencial dos } \\
\text { outros } \\
\text { concorrentes. }\end{array}$ \\
\hline $\mathrm{Z1}$ & $\begin{array}{c}\text { Ponto fixo para a } \\
\text { comercialização. } \\
\text { Próximo a outros } \\
\text { restaurantes. }\end{array}$ & $\begin{array}{l}\text { lluminação: Escura. Espaço: Ambiente } \\
\text { de rua, céu aberto, com mesas e cadeiras } \\
\text { de madeira disponíveis em um espaço na } \\
\text { calçada de outro local comercial. } \\
\text { Decoração: O trailer é decorado com } \\
\text { artigos orientais, há pouco espaço para } \\
\text { movimentação interna } \\
\text { armazenamento dos produtos. } \\
\text { Climatizado: Não. Som ambiente: Não. } \\
\text { Garçons: Uniformizados normalmente. }\end{array}$ & $\begin{array}{c}\text { Enfoca na } \\
\text { mobilidade. }\end{array}$ & Estar na rua. \\
\hline $\mathbf{Z 2}$ & $\begin{array}{l}\text { Não há } \\
\text { localização exata, } \\
\text { a proprietária } \\
\text { alterna entre } \\
\text { pontos da cidade } \\
\text { e da região. }\end{array}$ & $\begin{array}{l}\text { Iluminação: Depende do local em que se } \\
\text { instalará para atendimento. Espaço: } \\
\text { Ambiente de rua, sem local fixo para o } \\
\text { negócio, ao se deslocar para eventos, } \\
\text { feiras livres, pouco espaço interno. } \\
\text { Decoração: Nenhuma. Climatizado: Não. } \\
\text { Som ambiente: Não. Garçons: } \\
\text { Uniformizados normalmente. }\end{array}$ & $\begin{array}{l}\text { Convida o } \\
\text { cliente } \\
\text { apreciar o } \\
\text { alimento } \\
\text { oriental de } \\
\text { maneira } \\
\text { diferenciada, } \\
\text { isto é, em } \\
\text { quatro rodas. }\end{array}$ & $\begin{array}{c}\text { Possibilidade } \\
\text { de } \\
\text { deslocamento }\end{array}$ \\
\hline
\end{tabular}

Fonte: Elaborado pelos autores com base na pesquisa de campo. 
Algumas empresas $(\mathrm{X} 1, \mathrm{Y} 1, \mathrm{Z} 1)$ foram instaladas de maneira estratégica em ruas movimentadas e próximas a outros estabelecimentos comerciais de venda de alimentos, criando uma espécie de centro gastronômico nessas cidades.

Embora seja um trailer, que pode se deslocar pela cidade, a empresa Z1 atende em um local fixo, inutilizando a estratégia de mobilidade proporcionada pelo canal escolhido. $O$ principal motivo dessa decisão é a dificuldade em encontrar locais para a sua permanência, visto que é preciso autorização dos comerciantes que possuem pontos fixos, para que o trailer estacione na frente desses estabelecimentos. Além disso, foi apontada a indisponibilidade de energia elétrica para o funcionamento dos equipamentos utilizados no preparo e no armazenamento dos alimentos como outro problema à mobilidade, sendo necessário utilizar a energia elétrica da vizinhança comercial, após negociações com os empresários do local onde o trailer permanece.

A empresa Z2 utiliza a mobilidade como uma estratégia competitiva, fazendo uso também das redes sociais e aplicativos de mensagens para comunicação, uma vez que o food truck participa de eventos festivos, exposições, festivais de alimentos na cidade e na região, sempre informando sua localização aos clientes. Além de comparecer a eventos e exposições, o restaurante realiza entrega de pedidos nos locais onde o cliente se encontra, sempre anunciando nas redes sociais os horários e os bairros em que vai atender, de forma a criar e manter o relacionamento e a interação com os clientes.

Como era de se esperar, os ambientes (espaço físico) dos restaurantes que optaram por um canal de distribuição tradicional são os mais diferenciados, comparados aos demais estabelecimentos, devido ao espaço maior, possibilidade de iluminação cênica (ambiente) e decoração oriental sofisticada, local climatizado (empresa X1), além do som ambiente (empresa $\mathrm{X} 2$ ). Além destes fatores, o atendimento na empresa X1 é realizado por garçons vestidos com trajes orientais, a fim de interagir e proporcionar uma experiência mais completa aos clientes. Os gestores destes restaurantes reconhecem que o formato de canal tradicional adotado é um fator estratégico favorável, agregando valor (experiência) ao produto oferecido.

Os ambientes dos food trucks, diferentemente dos canais tradicionais, não oferecem uma boa iluminação e/ou luz cênica (ambiente). O fato de estar na rua, a céu aberto, não possibilita investimentos em um ambiente climatizado ou decoração sofisticada, por exemplo.

A estratégia de posicionamento baseado no valor percebido também foi identificada nas empresas de canais alternativos. Os restaurantes especializados em delivery transmitem mensagens de rapidez, agilidade, instantaneidade na confecção e entrega dos produtos, enquanto os food trucks evidenciam a mobilidade em seus slogans.

Para os gestores das empresas Z1 e Z2, o ambiente de rua chama a atenção por ser diferente e proporciona aos clientes um comportamento "desenvolto e desinibido", em especial àqueles que nunca tiveram a experiência de comer alimento oriental e, por isso, apresentam certo grau de timidez de entrarem em um restaurante tradicional, possivelmente por não estarem familiarizados com o hashi (tradicionais palitos utilizados como talheres nos países orientais).

A ideia de um ambiente mais informal observado nos formatos de canal de distribuição food truck, delivery e retirada no balcão permitem que os clientes se sintam despreocupados em relação às vestimentas, proporcionando, também, a conveniência da alimentação durante o deslocamento entre dois compromissos, como exemplo, trabalho-casa. 


\section{DISCUSSÃO}

Os gestores dos restaurantes de canais de distribuição tradicionais utilizam como estratégia o seu espaço físico/ambiente diferenciado. Para Hollebeek e Brodie (2009), essa estratégia possibilita uma maior interação com o cliente durante o atendimento, com funcionários utilizando vestimentas e acessórios da cultura oriental, combinado a um ambiente aconchegante que proporciona afetividade, com artigos decorativos. Esses fatores contribuem com uma atmosfera proporcionada pelos restaurantes orientais, isto é, aspectos relacionados às tradições e culturas. A atmosfera do ambiente é um elemento importante da experiência gastronômica, influenciando as emoções e as expectativas do cliente quanto à qualidade do serviço e, o seu efeito em restaurantes étnicos sobre a satisfação e fidelidade do consumidor pode variar dependendo de como o ambiente físico do restaurante é percebido (HA; JANG, 2010), sendo esse o entendimento dos gestores desses canais sobre a qualidade do produto e o atendimento ofertado. Liang e Chen (2020) explicam que o atendimento no local se torna diferenciado e mais competitivo, comparado aos demais canais de distribuição, justamente pela prestação do serviço estar diretamente relacionada à intangibilidade.

Por outro lado, as empresas especializadas em "delivery", ao oferecerem um espaço reduzido, estão mirando um menor aporte inicial de capital, comparado a um estabelecimento de canal de distribuição tradicional (McLAUGHLIN, 2009). Com uma estratégia relacionada ao baixo investimento do negócio, no que diz respeito a um espaço físico reduzido, sem os serviços de garçons ou decorações, é possível proporcionar, ainda, comodidade ao cliente que aguarda pelo produto no local, disponibilizando um ambiente iluminado e climatizado, e agilidade na entrega dos produtos, reduzindo o tempo de espera de quem busca o pedido.

A flexibilidade do food truck (Z2) deslocar-se até ao consumidor, em qualquer dia, horário e eventos festivos também foi verificada por Souza Bispo e Almeida (2020), ao mencionarem que os food trucks usualmente trabalham aos domingos, feriados e não apresentam horas fixas de trabalho, buscando um melhor atendimento ao consumidor. Reforçando a estratégia executada pelo empreendimento, Porter e Miller (1985) destacam que a vantagem estratégica só é alcançada pela empresa quando seus gestores implementam ações competitivas favoráveis, sustentáveis e lucrativas perante os concorrentes.

Assim, o restaurante $Z 2$ oferece, além da conveniência da mobilidade, a experiência além do consumo alimentício, ao usufruírem dos serviços oferecidos durante a refeição como um todo (RAMANATHAN; DI; RAMANATHAN, 2016).

Esses empreendimentos podem, ainda, utilizar estratégias de inovações sociais em serviços alimentares, ofertando alimentos saudáveis, modo de comunicação com os clientes e gestão específica na utilização do tempo e do espaço (SOUZA BISPO; ALMEIDA, 2020). Com foco ainda no social, a alimentação em ambientes de rua, tanto os foods trucks quanto os restaurantes que realizam entrega em balcão, disponibilizam, na verdade, um espaço acessível a uma maior diversidade de pessoas, democratizando o acesso à comida japonesa em termos físicos e monetários (SOUZA BISPO; ALMEIDA, 2020). Essa situação foi verificada neste estudo com os canais alternativos em ambientes de rua, que utilizam estratégias para um público de diferentes classes sociais, com preços acessíveis e ambientes mais informais e descontraídos. Além disso, a facilidade de acesso durante um percurso de ida ou volta a algum compromisso favorece a compra de alimentos por impulso, não planejada. Lee e Kacen (2008) destacam esse tipo de comportamento de compra baseada na emoção e atração pelo produto que leva ao desejo de consumo imediato. Um dos fatores identificados como influência no processo de decisão de compra do cliente, nos formatos food truck e retirada no balcão, é 
justamente esse comportamento de consumo irracional, baseado na emoção, dado a relevância dos alimentos comercializados, cujo aspecto visual estimula o consumo imediato, mesmo daqueles clientes com pouco tempo disponível.

Quando todas as empresas estudadas prestam serviços por meio do delivery, verificase uma clara demonstração de aplicação da estratégia de utilização de vários meios de distribuição para entregar o mesmo produto/serviço ao cliente, apresentando diferentes velocidades, experiências, ambientes, interação e grau de praticidade. Isso significa que agregar novos canais de distribuição continuamente, acompanhando o crescimento das compras de produtos e serviços por múltiplos canais é tendência também no setor de alimentação (BECK; RYGL, 2015). O delivery, embora não possa ser considerado uma inovação estratégica, e por vezes nem lucrativo, se consolida como um formato de distribuição essencial na estratégia das organizações frente aos novos modelos de comportamento do consumidor.

O posicionamento tradicional e alternativo no que diz respeito aos canais de comunicação utilizados pelas empresas parece ter relação com o formato de distribuição adotado como estratégia principal. Nesse sentido, os restaurantes tradicionais utilizam canais de comunicação tradicionais, como rádio, jornal, outdoor e até a lista telefônica. Liang e Chen (2020) mencionam que mesmo diante de avanços tecnológicos, ainda há o uso dessas estratégias convencionais em restaurantes, pois os gestores acreditam na eficiência do método em atrair clientes.

Por outro lado, o uso dos canais digitais, associados com maior ênfase aos restaurantes que utilizam formatos distributivos alternativos, proporcionam maior flexibilidade aos consumidores para realizarem pedidos sem saírem de casa. Enquanto Palmatier et al. (2016) alegam que a opção pelo digital refere-se aos agentes integrantes dos canais de distribuição buscarem entregar o produto da melhor forma possível ao usuário final, Sung, Tao e Slevitch (2020) reforçam o uso dessas ferramentas pelos restaurantes na intenção de contribuir para o aumento do poder de compra, criando sentimento e efeito positivo para o consumo, ao mesmo tempo em que seu uso em anúncios amplia o alcance e a atração de novos consumidores, com conteúdo disseminado em grupos e redes de amigos, com baixo custo e menor tempo.

O recebimento dos pedidos pelo WhatsApp, por exemplo, é uma das maneiras da empresa interagir instantaneamente, enviando fotos promocionais e informações dos produtos, com a certeza de o pedido foi entregue e lido pelo fornecedor (RODRIQUES, 2015).

Assim, o uso das mídias sociais pelas empresas reforça a intenção de uma estratégia de ampliação da interação com o consumidor, visualizando oportunidade de aproximação e de cocriação de valor (quando o cliente pode sugerir mudanças no pedido, por exemplo), ou promovendo um diálogo com troca de informações mútuas, mais humano, ao mesmo tempo que proporciona uma vivência maior, mais intensa e profunda da marca (KOTLER; KELLER, 2012; SALAZAR-SOLANO et al., 2018). Com o acesso dos gestores às informações dos consumidores, eles podem compreender preferências e opiniões acerca de seus empreendimentos, pratos e serviços oferecidos.

Enquanto o food truck (Z2) utiliza as mídias sociais de forma estratégica para relacionar-se com o consumidor e informá-lo sobre futuras localizações, atraídos pela gratuidade ou custo reduzido (a depender das escolhas dos gestores), Parsons e LepkowskaWhite (2018) apontam que um dos objetivos das empresas atuarem nas redes sociais é se conectar com diversos grupos sociais, sem distinção de classe, sexo e idade, propiciando interação e criando relacionamentos entre eles. 
Entretanto, os resultados demonstraram uma das dificuldades apresentada pelas empresas estudadas em administrar, de forma estratégica, as informações dos consumidores, relacionada à escassez de alguns recursos, como tempo de aplicação, conhecimento e investimento sobre o uso das ferramentas analíticas proporcionadas pelas redes sociais, afetando o monitoramento e o controle dos dados dos consumidores. Para Parsons e Lepkowska-White (2018), não conseguir identificar o público-alvo da comunicação, dificulta a verificação do retorno sobre o investimento realizado nessa estratégia de comunicação.

O posicionamento de mercado, verificado pelas mensagens de comunicação contidas nos slogans propagados pelos restaurantes estudados cria uma imagem na mente do consumidor. Neste caso, frases de divulgação dos negócios tradicionais transmitem mensagens convidativas para os clientes visitá-los, sendo perceptivo que as empresas valorizam o local e o ambiente oferecido. As empresas de canais tradicionais consideram que o valor oferecido aos clientes está relacionado diretamente aos ambientes disponibilizados, por proporcionarem um clima mais afetivo, comparado aos demais canais, sendo um dos determinantes da escolha dos clientes, juntamente com o serviço oferecido no local.

Por outro lado, a percepção dos gestores dos restaurantes que utilizam canais alternativos, sobre a imagem projetada no mercado é de que o valor percebido pelo cliente reside no fato dos serviços serem oferecidos em canais que consideram a mudança do comportamento do consumidor, ou seja, canais que incorporam elementos como habilidade, rapidez, comodidade na entrega, no caso dos food trucks, a conveniência do próprio restaurante ir ao seu encontro (ALFIERO; GIUDICE; BONADONNA, 2017).

A estratégia de comunicação dos foods trucks inclui atrativos customizados e linguagens não verbais, como o layout, a estrutura diferenciada, as imagens, cores, iluminação do trailer, além do tipo de alimento ofertado, como forma de atração e retenção de consumidor (SOUZA BISPO; ALMEIDA, 2020). O food truck Z1 reconhece que a estratégia de canal escolhida constitui-se em um diferencial, pelo fato de divulgar a mobilidade nos anúncios publicitários, embora o deslocamento não ocorra de fato, sendo a mensagem compartilhada (slogan) apenas um informe publicitário, sem que haja uma estratégia de posicionamento concreta.

\section{CONSIDERAÇÕES FINAIS}

O presente artigo analisou a forma de seleção de canais de distribuição e comunicação utilizados por restaurantes que oferecem alimentos orientais em municípios do interior do Estado de São Paulo.

As empresas conduzem a divulgação dos estabelecimentos, levando em consideração os diferenciais existentes ou sugeridos dos seus canais de distribuição, buscando uma posição competitiva favorável perante seus concorrentes, em relação à qualidade, preço e produtos comercializados. Nesse sentido, percebeu-se que não há um foco em posicionamentos distintos, embora as escolhas dos canais de distribuição e de comunicação possibilitem isso, se trabalhados para tal finalidade.

A estratégia de localização dos estabelecimentos focou em regiões onde já haviam estabelecimentos alimentares, de maneira a reduzir possíveis entradas de novos concorrentes do mesmo segmento de mercado, seja por meio de um canal de distribuição tradicional ou alternativo. Além disso, a estratégia escolhida para os ambientes oferecidos aos clientes tem por objetivo a agregação de valor por meio de um melhor atendimento em um local climatizado, com iluminação agradável, som ambiente e pouco ruído, como os restaurantes tradicionais, ou na agilidade e rapidez no atendimento, como as empresas que utilizam o 
delivery como principal canal distributivo. Nos casos de deliverys, há um menor grau de investimento de capital no ambiente e no número de funcionários, refletindo em preços mais acessíveis, comparados aos preços dos restaurantes de canais tradicionais.

Os food trucks utilizam-se do ambiente de rua como principal diferencial estratégico de seus estabelecimentos, proporcionando uma compra impulsionada pela possibilidade de oferecer os alimentos de maneira diferente, como uma inovação social e pela possibilidade de estar presente em diferentes eventos. Assim como, ocorre com o delivery, da entrega em domicílio e da possibilidade de realização dos pedidos sem a necessidade de o consumidor sair de casa, permitindo conforto e comodidade, de maneira combinada a um preço reduzido.

Quanto à comunicação utilizada nas empresas, percebeu-se o uso estratégico por meio da escolha de elementos - chave em sua eficácia, como os meios utilizados, a estrutura da mensagem e a interação com o consumidor. Os meios foram o tradicional e digital, ambos com alcance ao consumidor e público alvo selecionado, diversificando entre idades e classes sociais de consumo. $O$ uso da estrutura da mensagem e o tipo de linguagem verbal e não verbal estão atrelados ao uso dos diferentes tipos de canal de distribuição. Em que, a linguagem verbal é clara e convidativa às experiências relacionadas à cada canal de distribuição e a não verbal atrelada aos aspectos intangíveis do serviço oferecido e fatores visuais que contribuem na capacidade de oferecerem aos consumidores a oportunidade de apreciarem outra cultura, por meio da atmosfera exótica, enraizada em tradições orientais e locais.

O uso das mídias sociais reforçou a estratégia de aproximação e cocriação de valor, por meio de informações compartilhadas, diálogos e acesso às opiniões de consumo. Além disso, essas mídias apresentam um menor custo de investimento, a rápida disseminação de conteúdo, efeitos positivos da marca, aliado a um atendimento personalizado.

Porém, identificou-se que os gestores desconhecem o perfil do seu público-alvo, o que reduz os eventuais efeitos positivos da adoção dessa estratégia de comunicação.

As opiniões dos gestores, em relação às estratégias adotadas, estão de acordo com os canais de comunicação e distribuição utilizados, percebendo que as vantagens estratégicas, perante a concorrência, se dão por meio do ambiente e qualidade do atendimento prestado ao consumidor, acompanhando, assim, as mudanças no comportamento do mesmo.

Diante destes fatores, verificou-se que as decisões e desdobramentos estratégicos dos estabelecimentos são condizentes com os canais de distribuição e comunicação utilizados.

Diante da escolha do canal de distribuição utilizado pelos gestores e do perfil dos usuários, sugere-se realizar novas pesquisas, no mesmo recorte geográfico, porém com a perspectiva dos consumidores, como exemplo, se o canal de distribuição do local visitado é um fator determinante na decisão pelo local a ser frequentado.

Outras sugestões de pesquisa dizem respeito a replicar esse estudo em outras áreas de serviços e/ou em outros recortes geográficos, a fim de identificar as diferenças estratégicas entre os canais e regiões de estudo.

A principal contribuição da pesquisa, ao identificar os diferentes canais de distribuição e comunicação utilizados pelos restaurantes de comida oriental, está relacionada à descrição das estratégias utilizadas pelos gestores para cada canal, como forma de auxiliar esses empreendimentos na busca por vantagem competitiva temporária ou sustentável. Os gestores, ao reconhecerem as vantagens competitivas decorrentes da escolha dos diferentes canais, poderão investir em recursos para influenciar, de forma direta ou indireta, na agregação de valor ao produto oferecido. Esse estudo também serve de modelo para que 
outros gestores, de outras regiões e segmentos, potencializam o uso do formato de canal de distribuição escolhido, de forma a atrair e reter os clientes.

\section{REFERÊNCIAS}

ABF. Associação Brasileira de Franchising. 14 franquias de comida japonesa para investir e abrir o seu restaurante. 2018. Disponível em:

<https://www.portaldofranchising.com.br/franquias/franquias-de-comida-japonesa/>. Acesso em: 8 jul. 2020.

ABRESI: show confirma relevância para desenvolvimento para a culinária asiática. Asian \& Japan Food. Associação Brasileira de Gastronomia, Hospedagem e Turismo. São Paulo, set. 2016. Disponível em: <http://abresi.com.br/2016/08/asian-japan-food-show-confirmarelevancia-para-desenvolvimento-para-a-culinaria-asiatica/>. Acesso em: 17 fev. 2017.

ALFIERO, S.; LO GIUDICE, A.; BONADONNA, A. Street food and innovation: the food truck phenomenon. British Food Journal, Yorkshire, v. 119, n. 11, p. 2462-2476, nov. 2017. DOI: 10.1108/BFJ-03-2017-0179.

BARBOSA, L.; MADI, L., TOLEDO, M. A.; REGO, R. A. As tendências da alimentação. In: MORAES, L.C. Brasil Food Trends 2020. São Paulo, SP: Fiesp, Ital. 2010. cap. 3, p. 39-47.

BECK, N.; RYGL, D. Categorization of multiple channel retailing in Multi-, Cross-, and OmniChannel Retailing for retailers and retailing. Journal of Retailing and Consumer Services, Oxford, v. 27, n.1, p. 170-178, nov., 2015. DOI: 10.1016/j.jretconser.2015.08.001.

BERSELLI; C.; SANTOS, G. S.; RICCI, R. M. G.; DOS ANJOS, S. J. G. Los canales de distribución y las estrategias en los restaurantes: un estudio en Balneário Camboriú - Brasil. Estudios y perspectivas en turismo, Buenos Aires, v. 27, n. 3, p. 609-627, jul. 2018.

CARMO, J. A. Amizade, prazer e felicidade: relações entre atributos e valores na ótica de consumidores de comida japonesa. Contextus, Fortaleza, v. 10, n. 2, p. 67-82, set./ag. 2012. DOI: 10.19094/contextus.v10i1.320.

CASTILLO-VILLAR, F. R.; VILLASANTE-ARELLANO, A. J. Applying the multisensory sculpture technique to explore the role of brand usage on multisensory brand experiences. Journal of Retailing and Consumer Services, Eindhoven, v. 57, n.102185, p. 1-7, nov.2020. DOI: 10.1016/j.jretconser.2020.102185.

COUGHLAN, A. T; ANDERSON, E.; STERN, L. W.; EL- ANSARY, A. I. Canais de marketing e distribuição. Porto Alegre: Bookman, 2012.

CRESWELL, J. W. Investigação Qualitativa e Projeto de Pesquisa: Escolhendo entre Cinco Abordagens. Porto Alegre: Penso, 2014.

DE SOUZA BISPO, M.; ALMEIDA, L. L. Food trucks and food parks as a social innovation of eating out practice: A study in João Pessoa - Brazil. International Journal of Gastronomy and Food Science, Amsterdam, v. 20, n. 1, p. 1-8, jul. 2020. DOI: 10.1016/j.jjgfs.2020.100209. 
FITZSIMMONS, J. A.; FITZSIMMONS, M. J. Administração de Serviços: operações, estratégia e tecnologia da informação. Porto Alegre: Bookman, 2011.

FORMIGONI, I. Gastronomia asiática: levantamento da Francal Feiras estima faturamento anual em torno de R\$ 19 bilhões. FoodNews, São Paulo, 25 set. 2017. Disponível em: <http://www.foodnewsoficial.com.br/mercado/gastronomia-asiatica/>. Acesso em: 20 nov. 2018.

GIL, A. C. Métodos e técnicas de Pesquisa Social. São Paulo: Atlas, 2008.

HA, J.; JANG, S. Effects of service quality and food quality: The moderating role of atmospherics in an ethnic restaurant segment. International Journal of Hospitality Management, Florida, v. 29, n. 3, p. 520-529, aug. 2010. DOI: 10.1016/j.ijhm.2009.12.005.

HOLLEBEEK, L. D.; BRODIE, R. J. Wine service marketing, value co-creation and involvement: research issues. International Journal of Wine Business Research, Melbourne, v. 21, n. 4, p. 339-353, nov. 2009. DOI: 10.1108/17511060911004914.

IBGE - Instituto Brasileiro de Geografia e Estatística. Cadastro Central de Empresas, 2018. Disponível em: <https://sidra.ibge.gov.br/tabela/6450>. Acesso em: 13 jul. 2020.

KIM, M.; KIM, Y. CSR and Shareholder Value in the Restaurant Industry: The Roles of CSR Communication Through Annual Reports. Cornell Hospitality Quarterly, Arizona, v. 60, n. 1, 2019, p. 69-76, feb. 2019. DOI: 10.1177/1938965518777969.

KOTLER, P.; KARTAJAYA, H.; SETIAWAN, I. Marketing 3.0: as forças que estão definindo o novo marketing centrado no ser humano. Rio de Janeiro: Elsevier, 2012.

KOTLER, P., KELLER, K. L. Administração de Marketing. São Paulo: Pearson, 2012.

KOUFIE, M. G. E.; KESA, H. Millennials motivation for sharing restaurant dining experiences on social media, African Journal of Hospitality, Tourism and Leisure, Helderkruin, v. 9, n. 1, p. 1-25. 2020.

KOZLENKOVA, I. V., HULT, G. T. M., LUND, D. J., MENA, J. A., KEKEC, P. The role of marketing channels in supply chain management. Journal of Retailing, New York, v.91, n.4, p. 586-609, dez. 2015. DOI: 10.1016/j.jretai.2015.03.003.

LAKATOS, E. M.; MARCONI, M. A. Metodologia Científica. São Paulo: Atlas, 2008.

LEE, J. N.; KACEN, J. J. Cultural influences on consumer satisfaction with impulse and planned purchase decisions. Journal of Business Research, New York, v. 61, n. 3, p. 265-272, mar. 2008. DOI: 10.1016/j.jbusres.2007.06.006.

LIANG, X.; CHEN, H. A Qualitative Study on Local Individual- or Family Owned Casual Chinese Restaurants Marketing Communication Strategies. Journal of International Food \& 
Agribusiness Marketing, London, v. 1, n. 8, p. 1-22, jun. 2020. DOI: 10.1080/08974438.2020.1773368.

LIU, S. Q.; WU, L. L.; WANG, C-Y. A creative-mix or variety-mix fusion experience? Examining marketing strategies for ethnic fusion restaurants. International Journal of Hospitality Management, Florida, v. 89, n. 102596, p.1-11, aug. 2020. DOI 10.1016/j.ijhm.2020.102596.

LOVELOCK, C. H.; WIRTZ, J.; HEMZO, M. A. Marketing de serviços: pessoas, tecnologia e estratégia. São Paulo: Pearson, 2011.

MACHADO, J. G. C. F.; PIGATTO, G. Inovação de marketing para serviços de alimentação. In: ZUIN, L.F.S.; QUEIROZ, R. T. (Orgs.). Agronegócios: gestão, inovação e sustentabilidade. São Paulo: Saraiva, 2015, p. 199-225.

MAZZINI, A.; CHIAVENATO, J. J. Araçatuba: 100 anos de história. Araçatuba: UniSalesiano, 2008.

MCLAUGHLIN, K. Food truck nation. Wall Street Journal, 5 jun. 2009. Disponível em: < https://www.wsj.com/articles/SB10001424052970204456604574201934018170554>. Acesso em: 11 dez. 2017.

NEEDLES, A. M.; THOMPSON, G. M. Social media use in the restaurant industry: a work in progress. Cornell Hospitality Report, New York, v. 13, n. 7, p. 6-17. may. 2013.

OJI, O. N. E.; IWU, C. G.; HAYDAM, N. The use of social media marketing strategies by SMMEs in the hospitality sector in Cape Metropole, South Africa. African Journal of Hospitality, Tourism and Leisure, Helderkruin, v. 6, n.4, ap. 2017.

PALMATIER, R.; STERN, L.; EL-ANSARY, A.; ANDERSON, E. Marketing channel strategy. New York: Routledge, 2016.

PARSONS, A. L.; LEPKOWSKA-WHITE, E. Social Media Marketing Management: a Conceptual Framework, Journal of Internet Commerce, Washington, v. 17, n. 2, p. 81-95, feb. 2018. DOI: 10.1080/15332861.2018.1433910.

PIGATTO, G.; ALCANTARA, R. L. Relacionamento colaborativo no canal de distribuição: uma matriz para análise. Revista Gestão e Produção, São Carlos, v. 14, n. 1, p. 155-167, jan./abr. 2007.

PORTER, M. E.; MILLER, V. E. How information gives you competitive advantage. Harvard Business Review, Brighton, n. 85415, p. 149-152, jul. 1985.

PRATAMAWATY, B. B.; CAHYADINI, A.; JULIANJA, S.; VERONICA, G. S. Policy Communication Strategy of Restaurant Tax to Increase Bandung's Own-Source Revenue. International Conference on smart city innovation, Earth Environ, v. 248, n. 1, p. 1- 10, marc. 2018. DOI: 10.1088/1755-1315/248/1/012068. 
RAMANATHAN, R.; DI, Y.; RAMANATHAN, U. Moderating roles of customer characteristics on the link between service factors and satisfaction in a buffet restaurant. Benchmarking: An International Journal, Melbourne, v. 23, n. 2, p. 469-486, fev. 2016. DOI: 10.1108/BIJ-012015-0012.

RAUPP, F. M.; BEUREN, I. M. Metodologia da pesquisa aplicável às ciências sociais. In: BEUREN, Ilse Maria (Org.). Como elaborar trabalhos monográficos em contabilidade: teoria e prática. São Paulo: Atlas, 2003. p. 76-97.

RODRIGUES, G. Portal de Notícias Revista Exame. São Paulo, 4 nov. 2015. Disponível em: <http://exame.abril.com.br/pme/noticias/empresarios-apostam-no-atendimento-porwhatsapp>. Acesso em: 18 nov. 2015.

ROSENBLOOM, B. Canais de marketing: uma visão gerencial. São Paulo: Cengage Learning, 2014.

SALAZAR-SOLANO, V.; MORENO-DENA, J. M.; ROJAS-RODRIGUES, I. S.; ISLAS-OLAVARRIETA, L. A. Nivel de adopción de tecnologías de la información y la comunicación en empresas comercializadoras de mango en Nayarit - México. Estudios Gerenciales, Cali, v. 34, n. 148, p. 292-304, set. 2018. DOI: 10.18046/j.estger.2018.148.2639.

SANTOS, A. T.; ALVES, L.; BRAMBILLA, F. R. Cocriação de valor no varejo através da utilização das mídias sociais. Revista do CEPE, Santa Cruz do Sul, v.1, n, 43, p. 68-83, jan./jun. 2016. DOI: $10.17058 /$ cepe.v0i43.6994.

SILVA, V. L. S.; SOUZA, R. C.; SILVA, A. A. P.; SAES, M. S. M. Strategy management of multichannel distribution: a study in the Brazilian food industry. Production Journal, São Paulo, $v$. 26 , n.1, p. 115-128, jan./mar. 2016. DOI:

10.1590/0103-6513.039112.

SUNG, K.; TAO, C.W.; SLEVITCH, L. Restaurant chain's corporate social responsibility messages on social networking sites: The role of social distance. International Journal of Hospitality Management, New York, v. 85, n.1, p. 1-11. Feb., 2020. DOI:

10.1016/j.ijhm.2019.102429.

TELLES, R.; STREHLAU, V. I. Canais de marketing e distribuição. São Paulo: Saraiva Educação SA, 2017.

TUPÃ. Perfil da cidade. Prefeitura da Estância Turística de Tupã/SP. 2015. Disponível em: <https://www.tupa.sp.gov.br/conteudo/7/2/perfil-da-cidade.html>. Acesso em: 14 jul. 2020.

VERHOEF, P. C.; KANNAN, P. K.; INMAN, J. J. From Multi-Channel Retailing to Omni-Channel Retailing Introduction to the Special Issue on Multi-Channel Retailing. Journal of Retailing, Oxford, v. 91, n. 2, p.174-181, jun. 2015. DOI: 10.1016/j.jretai.2015.02.005. 
XUE, J.; LIANG, X.; XIE, T.; WANG, H. See now, act now: How to interact with customers to enhance social commerce engagement? Information \& Management, Amsterdam, v. 57, n. 6, p. 1-26, set. 2020. DOI: 10.1016/j.im.2020.103324.

YIN, R. K. Estudo de caso: planejamento e métodos. Porto Alegre: Bookman, 2005. 